\title{
Gas Chromatographic-Ion Trap Mass Spectrometric Analysis of Volatile Organic Compounds by Ion-Molecule Reactions Using the Electron-Deficient Reagent Ion $\mathrm{CCl}_{3}{ }^{+}$
}

\author{
Cheng-Zhong Wang, ${ }^{1,2}$ Yue Su, ${ }^{1}$ Hao-Yang Wang, ${ }^{2}$ Yin-Long Guo ${ }^{2}$ \\ ${ }^{1}$ Research Center for Health and Nutrition, Shanghai University of Traditional Chinese Medicine, 1200 Cailun Road, \\ Shanghai, 201203, China \\ ${ }^{2}$ Shanghai Mass Spectrometry Center, Shanghai Institute of Organic Chemistry, Chinese Academy of Sciences, 345 Lingling \\ Road, Shanghai, 200032, China
}

\begin{abstract}
When using tetrachloromethane as the reagent gas in gas chromatography-ion trap mass spectrometry equipped with hybrid ionization source, the cation $\mathrm{CCl}_{3}{ }^{+}$was generated in high abundance and further gas-phase experiments showed that such an electron-deficient reagent ion $\mathrm{CCl}_{3}{ }^{+}$could undergo interesting ion-molecule reactions with various volatile organic compounds, which not only present some informative gas-phase reactions, but also facilitate qualitative analysis of diverse volatile compounds by providing unique mass spectral data that are characteristic of particular chemical structures. The ion-molecule reactions of the reagent ion $\mathrm{CCl}_{3}{ }^{+}$with different types of compounds were studied, and results showed that such reactions could give rise to structurally diagnostic ions, such as $\left[\mathrm{M}+\mathrm{CCl}_{3}-\mathrm{HCl}\right]^{+}$for aromatic hydrocarbons, $[\mathrm{M}-\mathrm{OH}]^{+}$for saturated cyclic ether, ketone, and alcoholic compounds, $[\mathrm{M}-\mathrm{H}]^{+}$ ion for monoterpenes, $\mathrm{M}^{-+}$for sesquiterpenes, $\left[\mathrm{M}-\mathrm{CH}_{3} \mathrm{CO}\right]^{+}$for esters, as well as the further fragment ions. The mechanisms of ion-molecule reactions of aromatic hydrocarbons, aliphatic ketones and alcoholic compounds with the reagent ion $\mathrm{CCl}_{3}{ }^{+}$were investigated and proposed according to the information provided by MS/MS experiments and theoretical calculations. Then, this method was applied to study volatile organic compounds in Dendranthema indicum var. aromaticum and 20 compounds, including monoterpenes and their oxygen-containing derivatives, aromatic hydrocarbon and sesquiterpenes were identified using such ion-molecule reactions. This study offers a perspective and an alternative tool for the analysis and identification of various volatile compounds.
\end{abstract}

Key words: Ion-molecule reactions, $\mathrm{CCl} 3+$, Volatile organic compounds

Electronic supplementary material The online version of this article (doi:10.1007/s13361-011-0193-x) contains supplementary material, which is available to authorized users.

Correspondence to: Yue Su; e-mail: drsuyue@hotmail.com, Yin-Long Guo; e-mail: ylguo@sioc.ac.cn

\section{Introduction}

tudy of ion-molecule reaction and using this strategy for $\checkmark$ molecular identification are an important research field in analytical chemistry and organic mass spectrometry. Over 
the past decade, various mass spectrometric methods based on ion-molecule reactions have been explored in order to study organic reactions [1-3] and give deep insights into the fundamental physical and chemical properties of gas-phase ions such as gas-phase acidities, basicities, and bond energies [4-6]. Furthermore, ion-molecule reactions are also regarded as a useful tool for solving challenging analytical problems because these reactions are often highly selective and extremely fast, as well as combined with chromatographic separation methods for qualitative analysis of target compounds in complicated samples. Recently, more studies have focused on the development of mass spectrometric methods based on structurally diagnostic ion-molecule reactions and MS/MS techniques for identification and structural characterization of isomeric compounds by using selective reagents [719]. The demand for fast, highly selective and sensitive ionmolecule reactions in analytical applications stimulated researchers' interest in searching for new alternative reagents used for such purposes [20, 21]. Many unusual reagents, such as 1, 2-dibromoethane [22, 23], methyl iodide [24], furan [25, 26], tetrahydrofuran [27], dimethyl carbonate [28], ethers [2931], $\mathrm{HOO}^{-}$[32], and PFTBA [33, 34], have been developed and successfully utilized for the qualification and quantitation of compounds in complex matrices.

GC-MS technique combines high separation efficiency and high identification capacity in one and is an ideal method for analyzing volatile and semivolatile compounds in complex matrices. The analytical strategy coupling ion-molecule reactions with GC-MS is an alternative means for qualitative and quantitative analysis of organic compounds especially in complex matrices, enhancing the sensitivity and specificity of determination [35-39]. Recently, selective determination of pyridine alkaloids in tobacco was achieved by using PFTBA ions/analyte molecule reaction/ionization with ion trap mass spectrometry (ITMS) [33]. As a continuous effort in exploring the new type fast and structurally diagnostic ion-molecule reactions for qualitative analysis of small volatile compounds, we are searching for the fast and suitable electron-deficient reaction reagent ion towards these volatile compounds eluted from gas chromatography. In order to fulfill such a purpose, an ideal ion-molecule reaction should be fast enough to meet the requirement for detecting each gas chromatographic fraction, providing structurally diagnostic ion in the mass spectra and also being a convenient and stable method to be performed in an ion trap mass spectrometer.

In the present work, we report a detailed investigation of ion-molecule reactions using tetrachloromethane as the reagent gas for analysis of small molecule compounds by GC-ITMS. Tetrachloromethane is an inert organic solvent but shows significant reactivity when it is used as the reagent gas in ion-molecule reactions studied by GC-ITMS. The fragments generated through electron impact ionization are dominated by $\mathrm{CCl}_{3}{ }^{+}$in high abundance, which facilitate the isolation of the reagent ion and the understanding of the ion-molecule reaction mechanisms. Furthermore, the strong electron-deficient reagent ion $\mathrm{CCl}_{3}{ }^{+}$is liable to react with electron-rich compounds, enhancing the selectivity and sensitivity of determination.

The experimental results showed that the reagent ion $\mathrm{CCl}_{3}{ }^{+}$is an universal reaction reagent ion to react with various neutral volatile compounds: $\mathrm{CCl}_{3}{ }^{+}$can not only react with small volatile compounds, such as aromatic hydrocarbons, aliphatic ketones, alcoholic compounds, giving their structurally diagnostic product ions in mass spectra, but also perform the ion-molecule reaction with the most challenging target compounds- monoterpenes, sesquiterpenes, and their derivatives from medical herbs, to achieve selective qualitative analyses. Also, this developed analytical method based on such structurally diagnostic ion-molecule reactions was applied to analyze volatile organic compounds in Dendranthema indicum var. aromaticum, which enhanced the accuracy of qualitative analysis of volatile compounds.

\section{Experimental}

\section{Instrumentation}

All experiments were performed on a Varian 4000 GC/MS/MS system equipped with a commercial hybrid ionization source. Separations were performed in a cross-linked 5\%-phenyl-95\%dimethylpolysiloxane Varian FactorFour (VF-5 ms; Varian, Middelburg, The Netherlands) capillary column $(30 \mathrm{~m}$, $0.25 \mathrm{~mm}, 0.25 \mu \mathrm{m})$. The column oven temperature was programmed to rise from an initial temperature of $40{ }^{\circ} \mathrm{C}$ to $250{ }^{\circ} \mathrm{C}$ at a rate of $4{ }^{\circ} \mathrm{C} \mathrm{min}^{-1}$, and maintained at $250{ }^{\circ} \mathrm{C}$ for $5 \mathrm{~min}$. The injection port temperature and interface temperature were both $260{ }^{\circ} \mathrm{C}$. Helium was used as the carrier gas with a constant flow rate of $1.0 \mathrm{~mL} \mathrm{~min}^{-1}$. Split injection mode with a split ratio of 1:50 was employed. Mass spectral data discussed here were obtained from an ion trap mass spectrometer operated in the positive ion mode with a commercial hybrid ionization source and the software package provided by the vendor. The source and ion trap temperatures were $180^{\circ} \mathrm{C}$ and $200{ }^{\circ} \mathrm{C}$, respectively. Tetrachloromethane was used as the reagent gas in ion-molecule reactions study and the reagent pressure was adjusted to a nominal pressure of $50 \mu$ Torr (nominal pressure measured by an ion gauge). Neutral $\mathrm{CCl}_{4}$ molecules were ionized by electron impact in the hybrid source and the signal of $\mathrm{CCl}_{3}{ }^{+}$was maximized by varying the electron energy, emission current, and maximum reaction time. The isotopic cluster of $\mathrm{CCl}_{3}{ }^{+}$were isolated and transferred into the ion trap by ejecting all undesired ions through adjusting ejection amplitude. The isolated ions were allowed to react with neutral sample molecules eluted from GC capillary column to form product ions in the ion trap. Finally the reagent ions were ejected from the trap by setting the product ions scan mass range and afterwards the mass spectrum was acquired for the product ions. CID mass spectra were obtained with helium as the collision gas and the abundance of product ions was optimized by varying excitation amplitude ( $0-25 \mathrm{~V})$. In EI MS experiments, the electron energy was $70 \mathrm{eV}$ and the ion scan mass range was $m / z 40$ to 450 . 


\section{Sample Preparation}

Headspace extraction of the volatile components of herb sample was performed on the COMBI PAL system (Varian Inc.), which combines headspace auto-sampler, heater and agitator in one. The flowers of Dendranthema indicum var. aromaticum were collected at flowering stage from Shennongjia Alpine primitive forest of western Hubei Province, China. The flowers of Dendranthema indicum var. aromaticum $(0.5 \mathrm{~g})$ were put in $20 \mathrm{~mL}$ headspace vials and used for analysis of GCMS. The headspace equilibrium temperature of heating cabinet was set at $90^{\circ} \mathrm{C}$ for $10 \mathrm{~min}$ while being agitated at a speed of $300 \mathrm{r} \mathrm{min}^{-1}$ and finally $1000 \mu \mathrm{L}$ of headspace gas was injected into gas chromatograph to perform GC-MS analysis.

All samples considered in this work were obtained commercially and used as received.

\section{Computational Studies}

All theoretical calculations were carried out by using ab initio restricted Hatree-Fock method at STO-3 G basis set with Spartan molecular modeling software (PC Spartan Pro. 1.0.7.) [40-44]. The structures of ion species on the potential energy surface of the gas-phase reactions were optimized without imposing any constraints, and the relative energies of the optimized structures were calculated. All optimized structures were subjected to vibrational frequency analysis and the energies of the small neutral losses were also taken into consideration during calculations of the relative energies of every step in gas-phase reactions.

\section{Results and Discussion}

\section{Reagent Ion}

The selection of reagent gas and reagent ions is crucial to the selectivity and sensitivity of ion-molecule reactions. Here tetrachloromethane was selected as the reagent gas because of the above mentioned advantages. Figure S-1 (see Supporting Information) shows the reagent ions produced through electron impact ionization in the external source. The predominant ion at $\mathrm{m} / \mathrm{z} 117$ corresponding to $\mathrm{CCl}_{3}{ }^{+}$and its isotopic ions at $m / z 119,121$, and 123 were generated by eliminating chlorine atom from tetrachloromethane molecular ion. The reagent ions were transferred to the ion trap and then reacted with sample molecules to form product ions by ion-molecule reactions.

\section{Model Compounds}

Aromatic Hydrocarbons Aromatic hydrocarbons are liable to undergo electrophilic aromatic substitution reactions when attacked by electrophilic reagents due to the present of benzene ring in their structures. In the present study, ion-molecule reactions of the tetrachloromethane-derived reagent ion $\mathrm{CCl}_{3}{ }^{+}$ (the prominent ion at $\mathrm{m} / \mathrm{z} 117$ ) with benzene and toluene were performed to examine the reactivity of aromatic hydrocarbons.
The product ion spectrum for the reaction of the reagent ion $\mathrm{CCl}_{3}{ }^{+}$with benzene is shown in Figure S-2 (see Supporting Information). The ion at $\mathrm{m} / z 159$ corresponds to $\left[\mathrm{M}+\mathrm{CCl}_{3}-\right.$ $\mathrm{HCl}]^{+}$, which may be formed by a mechanism involving an addition-elimination process. However, the adduct ion [M+ $\left.\mathrm{CCl}_{3}\right]^{+}$at $\mathrm{m} / z 195$ was not detected. Consequently, this ionmolecule reaction sequence is likely initiated by an addition reaction between benzene and the reagent ion to form the unstable adduct ion, then a fast, complete elimination reaction occurred to remove a neutral of $\mathrm{HCl}$ from adduct ion, ultimately the stable product ions of $\left[\mathrm{M}+\mathrm{CCl}_{3}-\mathrm{HCl}\right]^{+}$were obtained and detected by mass spectrometer.

As for toluene at identical experimental conditions, toluene was found to react with $\mathrm{CCl}_{3}{ }^{+}$to form the product ion at $\mathrm{m} / z 173$ (Figure 1a). The ion at $\mathrm{m} / z 173$ corresponds to $\left[\mathrm{M}+\mathrm{CCl}_{3}-\mathrm{HCl}\right]^{+}$, but the adduct ion $\left[\mathrm{M}+\mathrm{CCl}_{3}\right]^{+}$was not detected. This experiment observation is similar to that of benzene. To further study the reaction mechanism, the structure of the product ion at $m / z 173$ was examined using collision-induced dissociation (CID) experiment. The dissociation of the product ion at $\mathrm{m} / \mathrm{z} 173$ yielded fragment ions at $m / z 102,103,137$, and 138 (Figure 1b). The fragment ion at $\mathrm{m} / \mathrm{z} 138$ is generated from the dissociation of the ion at $\mathrm{m} / \mathrm{z}$ 173 by loss of chlorine atom, while the ion at $m / z 137$ is generated by fragmentation of the ion at $m / z 173$ by loss of $\mathrm{HCl}$. The ion at $\mathrm{m} / z 103$ corresponds to the dissociation of the fragment ion at $\mathrm{m} / \mathrm{z} 138$ by eliminating chlorine atom. Loss of chlorine atom the ion at $\mathrm{m} / z 137$ or $\mathrm{HCl}$ from the ion at $m / z 138$ gives rise to the ion at $m / z 102$.

Theoretical calculation results demonstrated that the formation heat of the ion $\left[\mathrm{M}+\mathrm{CCl}_{3}-\mathrm{HCl}\right]^{+}$plus $\mathrm{HCl}$ is much lower than that of the adduct ion of $\left[\mathrm{M}+\mathrm{CCl}_{3}\right]^{+}$, and note in Figure 2 that formation of $\left[\mathrm{M}+\mathrm{CCl}_{3}-\mathrm{HCl}\right]^{+}$is predicted to be thermodynamically highly favored. The potential energy surface for the addition-elimination reaction of benzene presented in Figure 2 indicates that the additionelimination process takes place easily. Therefore, the plausible reaction and fragmentation mechanism of the ionmolecule reaction between aromatic hydrocarbons and $\mathrm{CCl}_{3}{ }^{+}$is proposed in Scheme 1 .

Collectively, because of the electron-rich property of benzene ring and the eletrophilicity of the reagent ion $\mathrm{CCl}_{3}{ }^{+}$, ion-molecule reactions between aromatic hydrocarbons and $\mathrm{CCl}_{3}{ }^{+}$give rise to the stable product ions corresponding to $\left[\mathrm{M}+\mathrm{CCl}_{3}-\mathrm{HCl}\right]^{+}$via an addition-elimination reaction mechanism. Hence, the product ion $\left[\mathrm{M}+\mathrm{CCl}_{3}-\mathrm{HCl}\right]^{+}$can be regarded as the structurally diagnostic ion to identify aromatic hydrocarbons using such ion-molecule reactions with the reagent ion $\mathrm{CCl}_{3}{ }^{+}$.

Aliphatic Ketones To test the reactivity of $\mathrm{CCl}_{3}{ }^{+}$toward aliphatic ketones, acetone and cyclohexanone were examined. Figure S-3 (see Supporting Information) shows the product ion spectra for ion-molecule reactions of acetone 

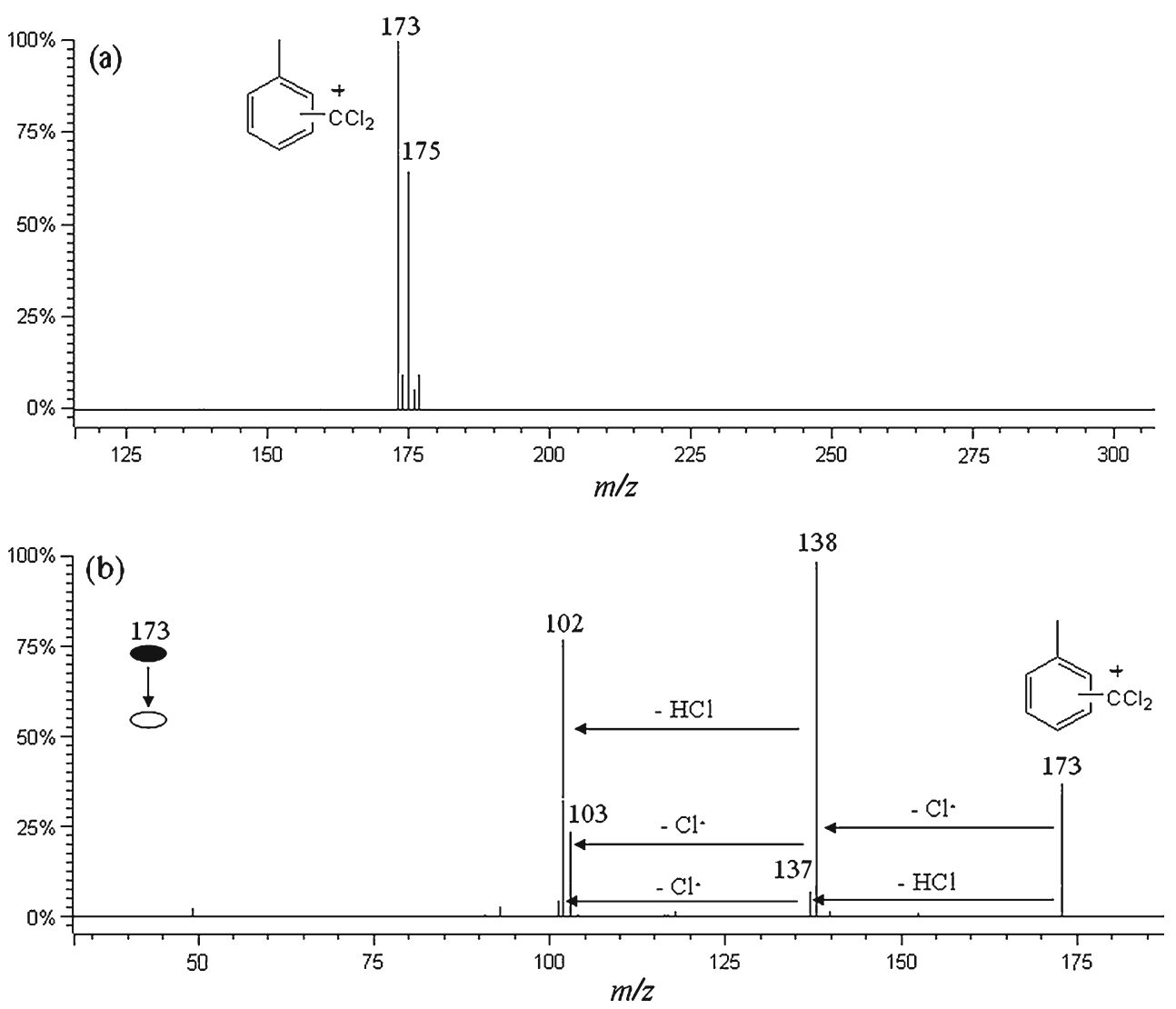

Figure 1. (a) Product ion mass spectrum for ion-molecule reaction of $\mathrm{CCl}_{3}{ }^{+}$with toluene, giving product ion at $\mathrm{m} / \mathrm{z}$ 173; (b) sequential product ion mass spectrum for CID of precursor ion of $\mathrm{m} / \mathrm{z} 173$, giving product ions at $\mathrm{m} / \mathrm{z} 138,137,103$, and 102

and cyclohexanone with $\mathrm{CCl}_{3}{ }^{+}$. The ions at $\mathrm{m} / \mathrm{z} 41$ and 81 corresponding to addition-elimination products $[\mathrm{M}-\mathrm{OH}]^{+}$ from the reaction of acetone and cyclohexanone were exclusively observed with no adduct ion or secondary reaction products being detected. This finding suggests that aliphatic ketones may undergo the reaction to form stable diagnostic product ions $[\mathrm{M}-\mathrm{OH}]^{+}$via an additionelimination reaction sequence. Three possible mechanisms

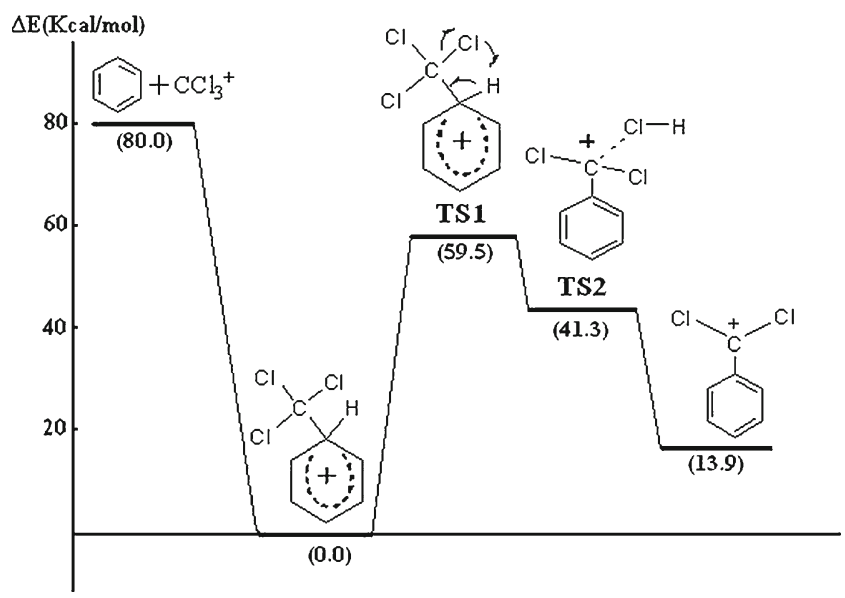

Figure 2. Schematic potential energy surface for ion-molecule reaction of $\mathrm{CCl}_{3}{ }^{+}$with benzene for this reaction are proposed in Scheme 2. In Path $A$ and Path $\mathrm{B}$, the reaction of $\mathrm{CCl}_{3}{ }^{+}$with aliphatic ketones are both initiated by an attack of the carbonyl oxygen to the carbon atom of $\mathrm{CCl}_{3}{ }^{+}$, leading to the formation of Compound 4 . Proton transfer to the carbonyl oxygen in this adduct via four-membered transition state(TS1) would result in Compound 5 in Path $\mathrm{A}$, then a $\mathrm{C}-\mathrm{O}$ bond cleavage via TS2 would lead to the formation of Compound 7 and neutral $\mathrm{HOCCl}_{3}$. However, in Path B, intramolecular proton transfer and $\mathrm{C}-\mathrm{Cl}$ bond cleavage in the adduct via six-membered transition state (TS3) induces the formation of Compound 6 and neutral $\mathrm{HCl}$. A heterolytic $\mathrm{C}-\mathrm{O}$ bond cleavage via TS4 follows to produce Compound 7 and neutral $\mathrm{COCl}_{2}$. As for Path $\mathrm{C}$, keto-enol tautomerism of aliphatic ketones takes place first, and then reacts with $\mathrm{CCl}_{3}{ }^{+}$to form Compound 5 . The reaction is completed by a $\mathrm{C}-\mathrm{O}$ bond cleavage via TS2 that ultimately form Compound 7 and neutral $\mathrm{HOCCl}_{3}$. The proposed mechanisms for the reaction of acetone with $\mathrm{CCl}_{3}{ }^{+}$were computationally examined, and a potential energy surface (PES) was constructed for the reaction, as shown in Figure 3. Analyses of Figure 3 show that the initial energy of Path $\mathrm{B}$ via six-membered transition state $\left(93.5 \mathrm{kcal} \mathrm{mol}^{-1}\right)$ is much lower than that of Path $\mathrm{C}$ via keto-enol tautomerism (113.1 $\left.\mathrm{kcal} \mathrm{mol}^{-1}\right)$. Moreover, the energy barrier for Path B (TS3, $78.8 \mathrm{kcal} \mathrm{mol}^{-1}$ ) is also much lower than that for Path A via four-membered 


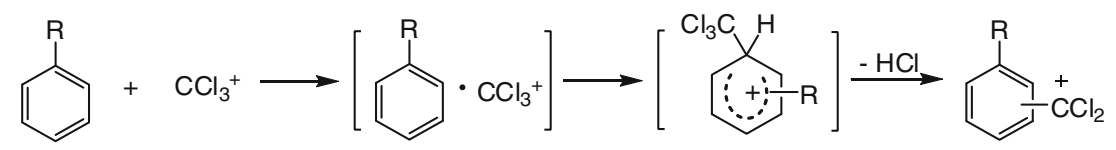

Scheme 1. The proposed mechanism of ion-molecule reactions of $\mathrm{CCl}_{3}{ }^{+}$with aromatic hydrocarbons

transition state (TS1, $97.6 \mathrm{kcal} \mathrm{mol}^{-1}$ ). These results indicate that the mechanism via six-membered transition state leading to form final product and neutral $\mathrm{COCl}_{2}$ is more favorable in thermodynamics.

Alcoholic Compounds To further probe the reactivity of $\mathrm{CCl}_{3}{ }^{+}$toward alcoholic compounds, analytes such as isopropanol, butanol, and allyl alcohol were examined. Figure S-4 (see Supporting Information) show the mass spectra for ion-molecule reactions with $\mathrm{CCl}_{3}{ }^{+}$of isopropanol, butanol, and allyl alcohol, respectively. The product ions at $\mathrm{m} / \mathrm{z} 43,57$, and 41 corresponding to [M $\mathrm{OH}]^{+}$from the reaction with isopropanol, butanol and allyl alcohol were formed exclusively with no detection of the adduct $\left[\mathrm{M}+\mathrm{CCl}_{3}\right]^{+}$. These experimental results indicate that an addition-elimination reaction sequence occurred when alcoholic compounds react with $\mathrm{CCl}_{3}{ }^{+}$, leading to the formation of the stable addition-elimination products. This reaction mechanism is consistent with the results from theoretical calculations as shown in Figure S-5 (see Supporting Information). Therefore, the possible reaction mechanism for ion-molecule reactions of alcoholic compounds with $\mathrm{CCl}_{3}{ }^{+}$is analogous to Path $\mathrm{C}$ in the possible mechanisms for ketones as shown in Scheme 2.

Saturated Cyclic Ethers The reactivity of the reagent ion $\mathrm{CCl}_{3}{ }^{+}$toward saturated cyclic ethers was studied by examining the reaction of $\mathrm{CCl}_{3}{ }^{+}$with tetrahydrofuran. The reaction of $\mathrm{CCl}_{3}{ }^{+}$with tetrahydrofuran is dominated by the product ion at $m / z 55$, which corresponds to the abstraction of a negatively charged group of $\mathrm{m} / \mathrm{z} 17$ (Figure S-6). This reaction is initiated by a highly exothermic addition of the ester oxygen to the reagent ion $\left(-100.7 \mathrm{kcal} \mathrm{mol}^{-1}\right)$. A heterolytic $\mathrm{C}-\mathrm{O}$ bond cleavage accompanied by a concerted 1,2-hydride shift occurs readily. Another additional, slightly exothermic 1,2hydride shift, intramolecular proton transfer to the ether oxygen via a four-membered transition state, and a $\mathrm{C}-\mathrm{O}$ bond heterolysis would lead to the formation of a low-energy allylic carbonication $\mathrm{C}_{4} \mathrm{H}_{7}{ }^{+}\left(\mathrm{m} / z\right.$ 55) and neutral $\mathrm{HOCCl}_{3} . \mathrm{HO}^{-}$ abstraction by $\mathrm{CCl}_{3}^{+}$from tetrahydrofuran is proposed in Scheme 3, which follows a similar mechanism as the reaction of $\mathrm{Cl}-\mathrm{P}^{+}-\mathrm{Cl}$ with tetrahydrofuran [45]. The overall process is estimated to be highly exothermic (by $21.4 \mathrm{kcal} \mathrm{mol}^{-1}$ ), and hence associated with a strong thermodynamic driving force.

Esters The reaction of $\mathrm{CCl}_{3}{ }^{+}$with butyl acetate was performed to test the reactivity of $\mathrm{CCl}_{3}{ }^{+}$toward esters. Figure S-7 shows the product ion mass spectrum for the reaction of $\mathrm{CCl}_{3}{ }^{+}$with butyl acetate. The predominant ions at $m / z 73$ and 57 correspond to $\left[\mathrm{M}-\mathrm{CH}_{3} \mathrm{CO}\right]^{+}$and $[\mathrm{M}-$ $\left.\mathrm{CH}_{3} \mathrm{CO}_{2}\right]^{+}$, respectively. This reaction is likely initiated by an addition-elimination reaction process between $\mathrm{CCl}_{3}{ }^{+}$and neutral butyl acetate to form adduct ions in two different

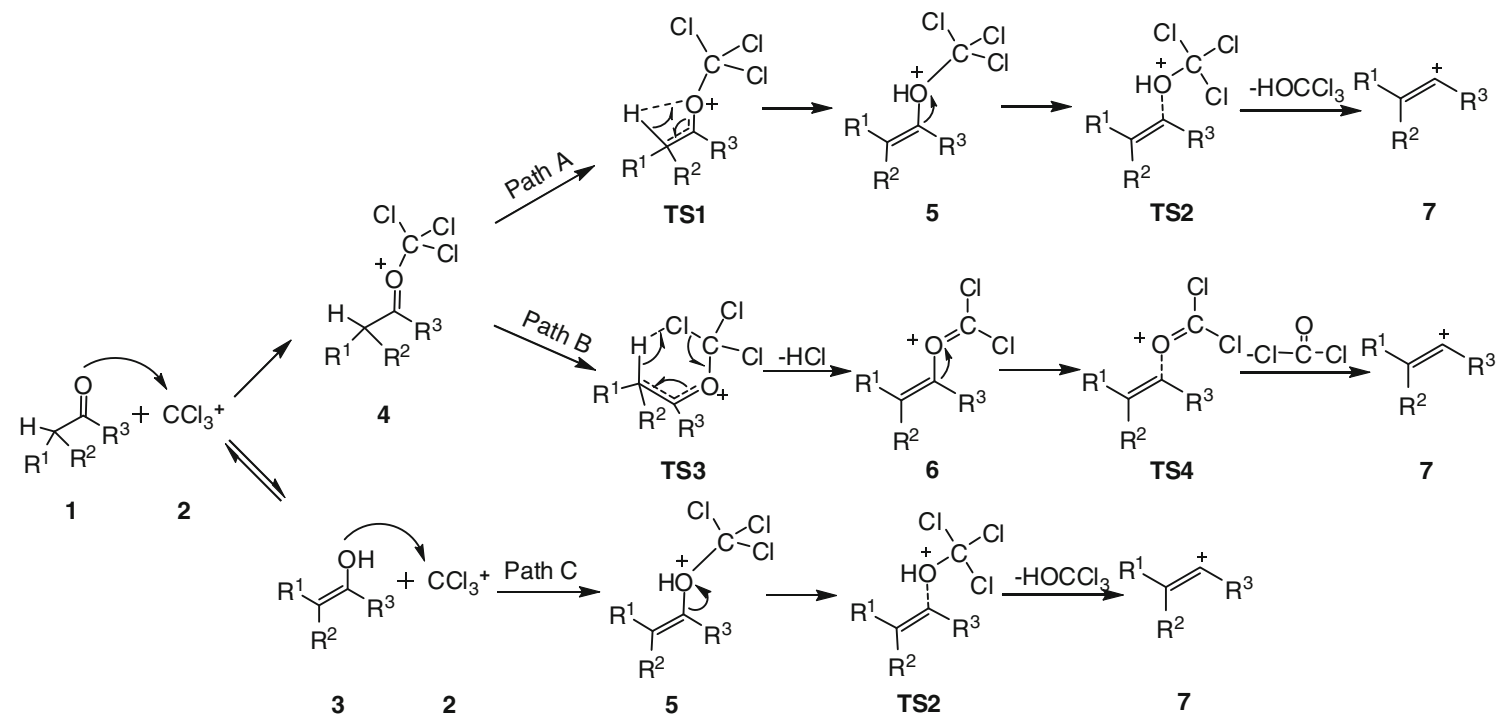

Scheme 2. The proposed mechanism of ion-molecule reactions of $\mathrm{CCl}_{3}{ }^{+}$with aliphatic ketones 


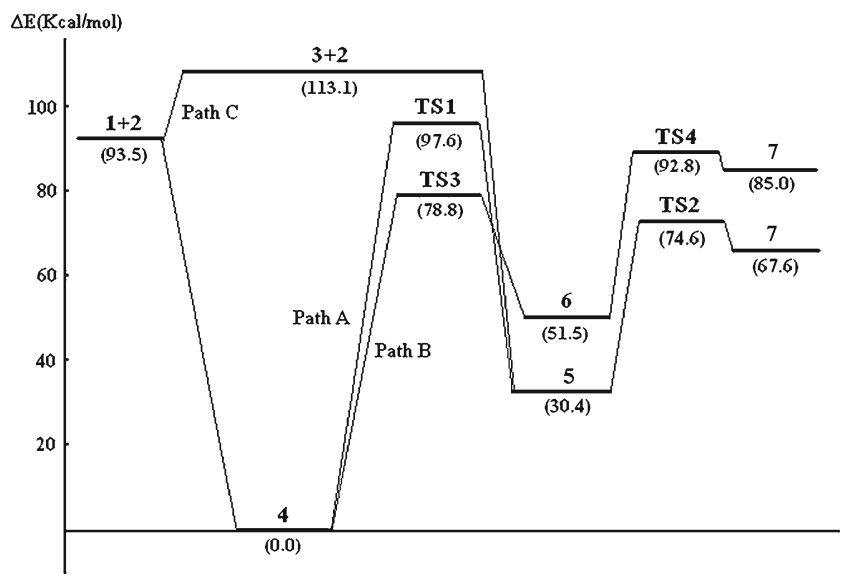

Figure 3. Schematic potential energy surface for ion-molecule reaction of $\mathrm{CCl}_{3}{ }^{+}$with acetone

pathways as shown in Scheme S-1(see Supporting Information). The dissociation of the adduct ions in two pathways yields the fragment ions at $m / z 73$ by Path A and $m / z 57$ by Path B, respectively. The computational results indicate that the formation processes of the product ions at $\mathrm{m} / \mathrm{z} 73$ and 57 from gas-phase reactions of $\mathrm{CCl}_{3}{ }^{+}$with butyl acetate are highly exothermic (by $53.1 \mathrm{kcal} \mathrm{mol}^{-1}$ in Path $\mathrm{A}$ for the ion at $m / z 73$ and $21.3 \mathrm{kcal} \mathrm{mol}^{-1}$ in Path B for the ion at $m / z 57$, respectively), and therefore favorable in thermodynamics.

Alkenes To probe the reactivity of $\mathrm{CCl}_{3}{ }^{+}$toward alkenes, 1 hexene was examined. The product ion mass spectrum for the reaction is shown in Figure $\mathrm{S}-8$ (see Supporting Information). The reaction of the reagent ion $\mathrm{CCl}_{3}^{+}$with 1 -hexene is dominated by the ions at 83 corresponding to $[\mathrm{M}-\mathrm{H}]^{+}$formed via hydride abstraction. The reaction mechanism is presented in Scheme S-2 (see Supporting Information). The overall process is estimated to be highly exothermic by $75.3 \mathrm{kcal} \mathrm{mol}^{-1}$, and hence associated with a strong thermodynamic driving force.
The excess energy released in the reaction process is more than enough to form the final products by loss of neutral $\mathrm{HCCl}_{3}$.

Hydroxyethers The reactivity of $\mathrm{CCl}_{3}{ }^{+}$toward hydroxyethers was also tested by examining the reaction of $\mathrm{CCl}_{3}{ }^{+}$ with tetrahydrofurfuryl alcohol. Figure S-9 (see Supporting Information) shows the product ion mass spectrum for the reaction of $\mathrm{CCl}_{3}{ }^{+}$with tetrahydrofurfuryl alcohol. The molecular ion at $m / z 102$ and the fragment ions at $m / z 84$ and 67 corresponding to $\left[\mathrm{M}-\mathrm{H}_{2} \mathrm{O}\right]^{+}$and $\left[\mathrm{M}-\mathrm{H}_{2} \mathrm{O}-\mathrm{OH}\right]^{+}$ were observed. This reaction is likely initiated by a charge transfer reaction to form tetrahydrofurfuryl alcohol molecule ions. Further dissociation of the molecule ions is followed leading to the formation of the product ions at $\mathrm{m} / \mathrm{z} 84$ and 67 by loss of neutral $\mathrm{H}_{2} \mathrm{O}$ and further loss of hydroxyl radical, respectively.

\section{Dendranthema Indicum var. Aromaticum}

Ion-molecule reaction has been proved to be an effective method for identification and characterization of organic compounds [7-39]. EI mass spectral search results for 20 compounds in Dendranthema indicum var. Aromaticum are listed in Table S-1. EI mass spectral library search may not be enough to identify the volatile compounds from medical herbs due to the complexity of their mass spectra. However, application of the analytical strategy combining ion-molecule reaction involving the reagent ion $\mathrm{CCl}_{3}{ }^{+}$with EI mass spectral library search for identification of such compounds can effectively enhance the accuracy of qualitative analysis.

This study on ion-molecule reactions indicates that structurally diagnostic product ions were generated when different types of compounds react with $\mathrm{CCl}_{3}{ }^{+}$, and the characteristic fragmentation ions are expected to be useful in improving the specificity of chemical qualitative analysis using such ion-molecule reactions. Thus the ion-molecule reactions involving the reagent ion $\mathrm{CCl}_{3}^{+}$
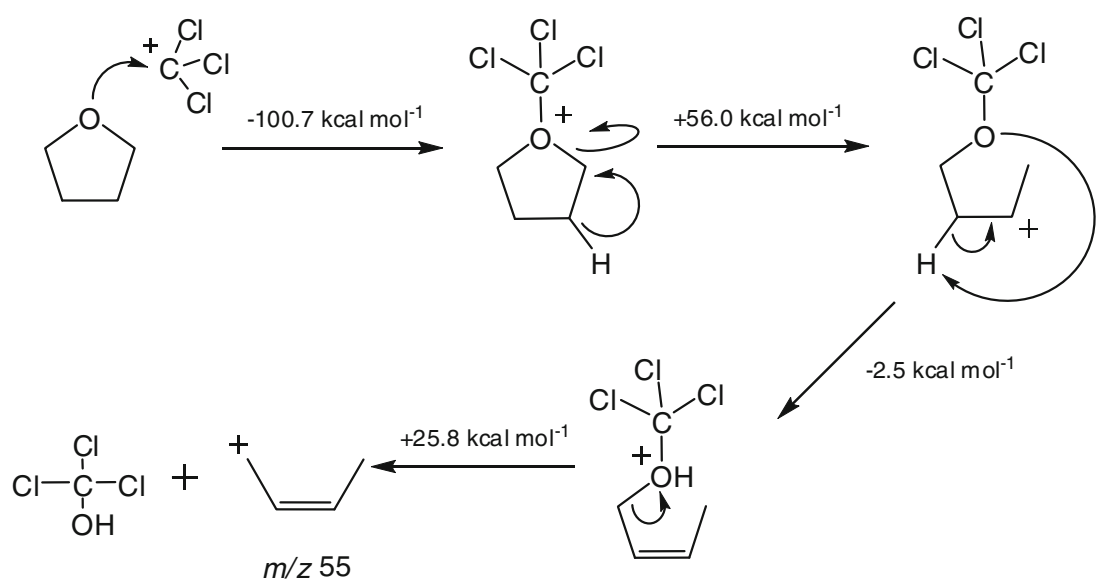

Scheme 3. The proposed mechanism of ion-molecule reaction of $\mathrm{CCl}_{3}{ }^{+}$with tetrahydrofuran 
can be utilized to identify volatile compounds from complex matrices by GC-MS with higher reliability and accuracy. Dendranthema indicum var. aromaticum, an important medical herb in China, contains a high number of volatile organic compounds, which complicate identification due to their similar mass spectra. To solve the problems occurred in qualitative analysis of volatile organic compounds, an analytical strategy coupling GCMS technique with ion-molecule reactions using $\mathrm{CCl}_{3}{ }^{+}$as the reagent ion was applied to determine aroma components emitted from Dendranthema indicum var. aromaticum. The volatile organic compounds were identified by structurally diagnostic product ions formed in ion-molecule reactions and EI mass spectral library search. The qualitative analysis results of volatile compounds are summarized in Table 1.

Different types of compounds, including monoterpenes and their oxygen-containing derivatives (ketones and alcohols), aromatic hydrocarbons, sesquiterpenes, and their alcoholic derivatives, were identified by ion-molecule reactions involving $\mathrm{CCl}_{3}{ }^{+}$. A variety of structurally diagnostic products are generated in these reactions. Generally, the most abundant product is formed either by hydride abstraction or addition-elimination reactions or charge transfer or charge transfer-elimination reactions. Usually just one reaction channel dominates for each compound (Table 1). The reactions are discussed in detail below.

Monoterpenes Similarly to the reaction of the reagent ion $\mathrm{CCl}_{3}{ }^{+}$with 1-hexene, when $\mathrm{CCl}_{3}{ }^{+}$at $\mathrm{m} / z 117$ reacts with monoterpenes, such as sabinene and $\alpha$-phellandrene, hydride abstraction reactions occur to give rise to the product ions $[\mathrm{M}-\mathrm{H}]^{+}$at $m / z 135$. The representative mass spectra for ion-molecule reactions of monoterpenes with $\mathrm{CCl}_{3}{ }^{+}$are shown in Figure S-10 (see Supporting Information).

The identification of $\alpha$-Phellandrene provides a typical example of the analytical utility of this method. The EI mass spectrum of the fourth compound in Table 1 is presented as Figure S-11a. There are two candidate compounds, $\alpha$ phellandrene and 4-methyl-benzenemethanol, found to possess higher mass spectral match degrees when they were preliminarily identified by mass spectral library search. Their mass spectra were similar as shown in Figure S-11b and c), so it is very difficult to identify this compound only by mass spectral search. However, the product ion at $\mathrm{m} / \mathrm{z} 135$ was obtained when it reacted with $\mathrm{CCl}_{3}{ }^{+}$(Figure S-11d). According to the reaction pattern of different classes of organic compounds, the ion at $\mathrm{m} / \mathrm{z} 135$ should be formed from $\alpha$-phellandrene via hydride abstraction. Hence, the compound was finally identified as $\alpha$-phellandrene.

Aromatic Hydrocarbon As an aromatic hydrocarbon, $p$ cymene reacted with $\mathrm{CCl}_{3}{ }^{+}$similarly to benzene and toluene except for the loss of propylene, giving the product ions at $m / z$ 173. Shown in Figure S-12a (see Supporting Information) is the product ion mass spectrum of the reaction of $\mathrm{CCl}_{3}{ }^{+}$with $p$-cymene, the ion at $\mathrm{m} / z 173$ corresponds to addition-elimination product $\left[\mathrm{M}+\mathrm{CCl}_{3}-\mathrm{C}_{3} \mathrm{H}_{6}-\mathrm{HCl}\right]^{+}$. However, the ions at $\mathrm{m} / \mathrm{z} 251$ and $\mathrm{m} / \mathrm{z} 215$ corresponding to adduct product $\left[\mathrm{M}+\mathrm{CCl}_{3}\right]^{+}$and addition-elimination product $\left[\mathrm{M}+\mathrm{CCl}_{3}-\mathrm{HCl}\right]^{+}$were not observed. Collision-induced dissociation of the product ion at $m / z 173$, shown in Figure S-12b (see Supporting Information), produces a fraction of the ion population at $\mathrm{m} / \mathrm{z} 138,137,103$, and 102, which is analogous to that of toluene shown in Figure 1. Hence, the reaction process of $p$-cymene with $\mathrm{CCl}_{3}{ }^{+}$is illustrated in Scheme S-3 (see Supporting Information). Furthermore, EI mass spectral search results show that the possible candidates of this compound are $p$-cymene, 4-ethyl$o$-xylene, and 1,3,8-p-menthatriene. Analyses of their structures indicate that $p$-cymene and 4-ethyl-o-xylene are aromatic compounds, while 1,3,8-p-menthatriene is an alkene compound. Therefore, the reaction of $\mathrm{CCl}_{3}{ }^{+}$with 1,3,8-p-menthatriene should follows a similar mechanism as that for 1-hexene to form the product ions at $\mathrm{m} / \mathrm{z} 133$ corresponding to $[\mathrm{M}-\mathrm{H}]^{+}$; while the reactions of $p$-cymene and 4-ethyl-o-xylene with $\mathrm{CCl}_{3}{ }^{+}$should follow a similar mechanism as that for benzene and toluene, forming the product ions corresponding to $\left[\mathrm{M}+\mathrm{CCl}_{3}-\mathrm{HCl}\right]^{+}$. However, comparing with 4-ethyl-o-xylene, further fragmentation of such product ions of $p$-Cymene would lead to the formation of more stable product ions corresponding to $\left[\mathrm{M}+\mathrm{CCl}_{3}-\right.$ $\left.\mathrm{C}_{3} \mathrm{H}_{6}-\mathrm{HCl}\right]^{+}$by loss of propylene. The principle of the reaction trends with different compounds and the diagnostic product ions help to identify the volatile compounds. These results further validate this compound should be $p$-cymene.

Monoterpene Alcohols and Ketones Figure S-13 (see Supporting Information) shows the product ion spectra of the reactions of monoterpene alcohols and ketones, including $\beta$-linalool, $\beta$-thujone, and camphor, with $\mathrm{CCl}_{3}{ }^{+}$, which showed the addition-elimination product ions $[\mathrm{M}-\mathrm{OH}]^{+}$at $\mathrm{m} / z 137$ and 135. The formation mechanism of $[\mathrm{M}-\mathrm{OH}]^{+}$is analogous to the case of aliphatic ketones and alcohols discussed above. However, as an alcoholic compound, $\gamma$ eudesmol shows different reactivity toward the reagent ion $\mathrm{CCl}_{3}{ }^{+}$, forming the product ion at $\mathrm{m} / z 204$ corresponding to $\left[\mathrm{M}-\mathrm{H}_{2} \mathrm{O}\right]^{+}$via charge transfer-elimination reaction process. To probe such unique product, the reaction of 2tetradecanol with the reagent ion $\mathrm{CCl}_{3}{ }^{+}$was examined. Similarly to $\gamma$-eudesmol, the product ion of this reaction was found at $m / z 196$ corresponding to $\left[\mathrm{M}-\mathrm{H}_{2} \mathrm{O}\right]^{+}$, as shown in Figure S-14 (see Supporting Information). Analyses of the reactions of monoterpenes and sesquiterpenes with the reagent ion $\mathrm{CCl}_{3}{ }^{+}$indicate that the reaction mechanisms were changed from hydride abstraction (essentially is one of addition-elimination reactions) to charge transfer reaction, which may be caused by the differences of the collision cross sections concerning the exact structures and molecular 
Table 1. Identification of Volatile Organic Compounds in Dendranthema indicum var. aromaticum by Ion-Molecule Reaction Involving the Reagent Ion $\mathrm{CCl}_{3}^{+}$

\begin{tabular}{|c|c|c|c|}
\hline Compounds (M. W.) & Chemical structures & Product ions $(\mathrm{m} / \mathrm{z})$ & Gas-phase reactions \\
\hline \multicolumn{4}{|l|}{ Monoterpenes } \\
\hline$\alpha$-Thujene (136) & & {$[\mathrm{M}-\mathrm{H}]^{+}(135)$} & Hydride abstraction \\
\hline$\alpha$-Pinene (136) & & {$[\mathrm{M}-\mathrm{H}]^{+}(135)$} & Hydride abstraction \\
\hline Sabinene (136) & & {$[\mathrm{M}-\mathrm{H}]^{+}(135)$} & Hydride abstraction \\
\hline$\alpha$-Phellandrene (136) & & {$[\mathrm{M}-\mathrm{H}]^{+}(135)$} & Hydride abstraction \\
\hline$\alpha$-Terpinene (136) & & {$[\mathrm{M}-\mathrm{H}]^{+}(135)$} & Hydride abstraction \\
\hline
\end{tabular}

Aromatic hydrocarbon

p-Cymene (134)

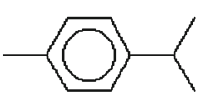

$\left[\mathrm{M}+\mathrm{CCl}_{3}-\mathrm{C}_{3} \mathrm{H}_{6}-\mathrm{HCl}\right]^{+}(173)$

Addition-Elimination

Ketones

$\alpha$-Thujone (152)

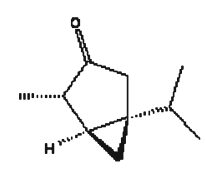

$[\mathrm{M}-\mathrm{OH}]^{+}(135)$

Addition-Elimination

$\beta$-Thujone (152)

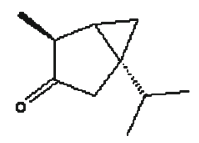

$[\mathrm{M}-\mathrm{OH}]^{+}(135)$

Addition-Elimination

Camphor (152)

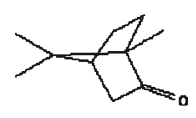

$[\mathrm{M}-\mathrm{OH}]^{+}(135)$

Addition-Elimination 
Table 1. (continued)

Compounds (M. W.)

Saturated cyclic ether

Eucalyptol (154)

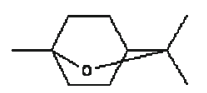

$[\mathrm{M}-\mathrm{OH}]^{+}(137)$

Addition-Elimination

Ester

Bornyl acetate (196)<smiles>CC(=O)OC1CC2(C)CCC1(C)C2</smiles>

$\left[\mathrm{M}-\mathrm{CH}_{3} \mathrm{CO}\right]^{+}(153)$

$\left[\mathrm{M}-\mathrm{CH}_{3} \mathrm{CO}_{2}\right]^{+}(135)$

Addition-Elimination

Hydroxyethers

cis-Linalool oxide (furanoid)

(170)

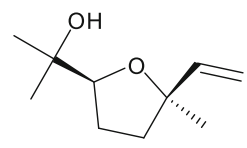

trans-Linalool

oxide

(furanoid) (170)

cis-Linalool oxide (pyranoid)

trans-Linalool

oxide

(pyranoid) (170)

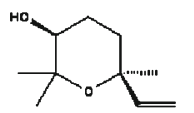

$\left[\mathrm{M}-\mathrm{H}_{2} \mathrm{O}\right]^{+}(152)$

$\left[\mathrm{M}-\mathrm{H}_{2} \mathrm{O}-\mathrm{OH}\right]^{+}(135)$

$\left[\mathrm{M}-\mathrm{H}_{2} \mathrm{O}\right]^{++}(152)$

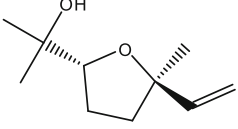

$\left[\mathrm{M}-\mathrm{H}_{2} \mathrm{O}-\mathrm{OH}\right]^{+}(135)$

$\left[\mathrm{M}-\mathrm{H}_{2} \mathrm{O}\right]^{+}(152)$

$\left[\mathrm{M}-\mathrm{H}_{2} \mathrm{O}-\mathrm{OH}\right]^{+}(135)$

$\left[\mathrm{M}-\mathrm{H}_{2} \mathrm{O}\right]^{++}(152)$

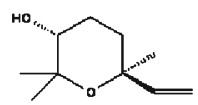

Charge transfer -Elimination

Charge transfer -Elimination

Charge transfer -Elimination

Charge transfer -Elimination 
Table 1. (continued)

\begin{tabular}{lll}
\hline Compounds (M. W.) & Gas-phase reactions \\
\hline Sesquiterpenes & Chemical structures & Charge transfer \\
Germacrene $\mathrm{D}$ (204) & Charge transfer & Charge transfer
\end{tabular}

weights of compounds. Accordingly, the reactions of monoterpene and sesquiterpene alcohols with the reagent ion $\mathrm{CCl}_{3}{ }^{+}$likely follow a similar tendency to form the product ions corresponding to $[\mathrm{M}-\mathrm{OH}]$ and $\left[\mathrm{M}-\mathrm{H}_{2} \mathrm{O}\right]^{+}$ via addition-elimination reaction and charge transferelimination reaction, respectively. These findings indicate that the observed final products of the reaction of alcoholic compounds with the reagent ion $\mathrm{CCl}_{3}{ }^{+}$depend on their exact structures and molecular weights. Generally, alcoholic compounds with small molecular weight react with $\mathrm{CCl}_{3}{ }^{+}$tend to form the products corresponding to $[\mathrm{M}-\mathrm{OH}]^{+}$via addition-elimination reaction process, while the reactions of $\mathrm{CCl}_{3}{ }^{+}$with alcohols with large molecular weights are likely to generate final products corresponding to $\left[\mathrm{M}-\mathrm{H}_{2} \mathrm{O}\right]^{++}$via charge transferelimination reaction. These results further demonstrate that such ion-molecule reactions involving $\mathrm{CCl}_{3}{ }^{+}$can be utilized as a complementary method to identify alcoholic compounds, and the analytical strategy combining EI mass spectral library search with such ion-molecule reactions involving $\mathrm{CCl}_{3}{ }^{+}$can effectively enhance the accuracy of qualitative analysis of alcoholic compounds.

Saturated Cyclic Ether $\mathrm{HO}^{-}$abstraction by the reagent ion $\mathrm{CCl}_{3}{ }^{+}$from Eucalyptol (to yield the ion at $\mathrm{m} / \mathrm{z} 135$, Table 1) likely follows a similar mechanism as that for tetrahydrofuran. Meanwhile, EI mass spectral search results of this compound are eucalyptol, trifluoroacetyl-alpha-terpineol, and terpin hydrate. Analyses of their structures show that eucalyptol is most likely to undergo the reaction process as that for tetrahydrofuran to produce the product ion at $\mathrm{m} / \mathrm{z}$ 135. Hence, identification of this compound can be effectively performed by EI mass spectral search and ionmolecule reaction involving $\mathrm{CCl}_{3}{ }^{+}$.

Ester The reaction of bornyl acetate with $\mathrm{CCl}_{3}{ }^{+}$gives product ions at $\mathrm{m} / \mathrm{z} 153$ and 135 corresponding to [M $\left.\mathrm{CH}_{3} \mathrm{CO}\right]^{+}$and $\left[\mathrm{M}-\mathrm{CH}_{3} \mathrm{CO}_{2}\right]^{+}$, respectively. The products indicate that bornyl acetate likely undergoes an additionelimination reaction to form stable fragment ions, which follows the same reaction process as that for butyl acetate. Therefore, such structurally diagnostic products formed in the reactions of esters with $\mathrm{CCl}_{3}{ }^{+}$can be utilized for complementary identification of esters.

Hydroxyethers The reactions of $\mathrm{CCl}_{3}{ }^{+}$with linalool oxides likely follow the same fashion as that of tetrahydrofurfuryl alcohol. While linalool oxides, such as cis-linalool oxide and trans-linalool oxide, react with $\mathrm{CCl}_{3}{ }^{+}$, a two-step reaction, including charge transfer-elimination steps, proceeds to give product ions at $\mathrm{m} / z 152$ and 135 but with no detection of the molecule ions at $\mathrm{m} / \mathrm{z} 170$. The representative product ion mass spectra are shown in Figure S-15 (see Supporting Information). The ion at $\mathrm{m} / \mathrm{z} 152$ is the first-generation product ion corresponding to $\left[\mathrm{M}-\mathrm{H}_{2} \mathrm{O}\right]^{+}$, while the loss of hydroxyl group from the ion at $\mathrm{m} / \mathrm{z} 152$ gives rise to the ion $\left[\mathrm{M}-\mathrm{H}_{2} \mathrm{O}-\mathrm{OH}\right]^{+}$at $m / z 135$.

Sesquiterpenes Similarly to ethers [45], charge transfer is thermodynamically favorable for terpene compounds with lower ionization energies. In ion-molecule reactions of $\mathrm{CCl}_{3}{ }^{+}$with sesquiterpenes, charge transfer is exothermic for sesquiterpenes with ionization energies less than $8.78 \mathrm{eV}$ 
(IE [46] of $\mathrm{CCl}_{3}^{+}$), i.e., $\alpha$-humulene (IE [47] $8.19 \mathrm{eV}$ ), $\beta$ caryophyllene (IE [47] $8.27 \mathrm{eV}$ ). For these sesquiterpenes, charge transfer dominates the reactions with $\mathrm{CCl}_{3}{ }^{+}$. When sesquiterpene compounds react with $\mathrm{CCl}_{3}{ }^{+}$, similar gasphase charge transfer reaction occurs to give their radical cations $\mathrm{M}^{+}$at $\mathrm{m} / \mathrm{z}$ 204. Figure S-16 (see Supporting Information) is the product ion spectra of the reactions of germacrene $\mathrm{D}$ and $\delta$-cadinene with $\mathrm{CCl}_{3}{ }^{+}$, showing the gasphase reactions of volatile sesquiterpene compounds with $\mathrm{CCl}_{3}{ }^{+}$to give their radical cations at $m / z 204$.

\section{Conclusions}

In this work, we studied the ion-molecule reactions between various organic compounds and the electron-deficient reagent ion $\mathrm{CCl}_{3}{ }^{+}$, generated by using tetrachloromethane as the reagent gas, by gas chromatography-ion trap mass spectrometry equipped with hybrid ionization source. The results show that structurally diagnostic product ions have been formed in ion-molecule reactions of different types of compounds with $\mathrm{CCl}_{3}{ }^{+}$. Hence, such ion-molecule reactions involving the reagent ion $\mathrm{CCl}_{3}{ }^{+}$can be utilized as an effective and complementary method to improve the accuracy of structural analysis of volatile organic compounds by GC-MS.

\section{Acknowledgments}

The authors gratefully acknowledge the National Natural Science Foundation of China (no. 20875097, 20902104, 21072215), the Innovation Program of Shanghai Municipal Education Commission (no. 09YZ121), Chinese Academy of Sciences (YZ200938), and the Natural Science Foundation of Shanghai (no. 09ZR1431900) for providing financial support for this work.

\section{References}

1. Feng, W.Y., Gronert, S.: Gas phase organic ion-molecule reaction chemistry. Annu. Rep. Prog. Chem. B 95, 349-372 (1999)

2. Hase, W.L.: Simulations of gas-phase chemical reactions: Applications to $\mathrm{S}_{\mathrm{N}} 2$ nucleophilic substitution. Science 266, 998-1002 (1994)

3. Butschke, B., Tabrizi, S.G., Schwarz, H.: Ion-molecule reactions of "Rollover" cyclometalated $\left[\mathrm{Pt}(\text { bipy-H) }]^{+}\right.$(bipy $=2,2^{2}$-bipyridine) with dimethyl ether in comparison with dimethyl sulfide: An experimental/ computational study. Chem. Eur. J. 16, 3962-3969 (2010)

4. McDonald, R.N., Chowdhury, A.K.: Hypovalent radicals. 13. Gasphase nucleophilic reactivities of phenylnitrene $\left(\mathrm{PhN}^{\circ}\right)$ and sulfur anion radicals $\left(\mathrm{S}^{-}\right)$at $\mathrm{sp}^{3}$ and carbonyl carbon. J. Am. Chem. Soc. 105, 198$207(1983)$

5. Gronert, S.: Mass spectrometric studies of organic ion-molecule reactions. Chem. Rev. 101, 329-360 (2001)

6. He, P., Guo, Y.L., Zhu, S.Z.: Study on the reactions of pyridine with fluorine-containing compounds in the gas phase by electron impact/ Fourier transfer ion cyclotron resonance mass spectrometry. J. Fluorine Chem. 125, 1537-1541 (2004)

7. Moraes, L.A.B., Gozzo, F.C., Eberlin, M.N., Vainiotalo, P.: Transacetalization with acylium ions. A structurally diagnostic ion-molecule reaction for cyclic acetals and ketals in the gas phase. J. Org. Chem. 62, 5096-5103 (1997)

8. Brodbelt, J.S.: Analytical applications of ion-molecule reactions. Mass Spectrom. Rev. 16, 91-110 (1997)
9. Eberlin, M.N.: Structurally diagnostic ion-molecule reactions: Class and functional-group identification by mass spectrometry. J. Mass Spectrom. 41, 141-156 (2006)

10. Mosi, A.A., Cullen, W.R., Eigendorf, G.K.: Ion-molecule reactions of perfluorotributylamine (FC43) cations with polycyclic aromatic hydrocarbons in a quadrupole ion trap. Int. J Mass Spectrom 190/191, 195207 (1999)

11. Fu, M.K., Duan, P.G., Li, S., Eismin, R.J., Kenttämaa, H.I.: An ionmolecule reaction for the identification of analytes with two basic functional groups. J. Am. Soc. Mass Spectrom. 20, 1251-1262 (2009)

12. Somuramasami, J., Kenttämaa, H.I.: Evaluation of a novel approach for peptide sequencing: Laser-induced acoustic desorption combined with $\mathrm{P}$ $\left(\mathrm{OCH}_{3}\right)_{2}$ chemical ionization and collision-activated dissociation in a Fourier transform ion cyclotron resonance mass spectrometer. J. Am. Soc. Mass Spectrom. 18, 525-540 (2007)

13. Somuramasami, J., Winger, B.E., Gillespie, T.A., Kenttämaa, H.I.: Identification and counting of carbonyl and hydroxyl functionalities in protonated bifunctional analytes by using solution derivatization prior to mass spectrometric analysis via ion-molecule reactions. J. Am. Soc. Mass Spectrom. 21, 773-784 (2010)

14. Watkins, M.A., Price, J.M., Winger, B.E., Kenttämaa, H.I.: Ionmolecule reactions for mass spectrometric identification of functional groups in protonated oxygen-containing monofunctional compounds. Anal. Chem. 76, 964-976 (2004)

15. Watkins, M.A., Winger, B.E., Shea, R.C., Kenttämaa, H.I.: Ionmolecule reactions for the characterization of polyols and polyol mixtures by ESI/FT-ICR Mass Spectrometry. Anal. Chem. 77, 13851392 (2005)

16. Campbell, K.M., Watkins, M.A., Li, S., Fiddler, M.N., Winger, B., Kenttämaa, H.I.: Functional group selective ion-molecule reactions: Mass spectrometric identification of the amido functionality in protonated monofunctional compounds. J. Org. Chem. 72, 3159-3165 (2007)

17. Watkins, M.A., WeWora, D.V., Li, S., Winger, B.E., Kenttämaa, H.I.: Compound screening for the presence of the primary $\mathrm{N}$-Oxide functionality via ion-molecule reactions in a mass spectrometer. Anal. Chem. 77, 5311-5316 (2005)

18. Fu, M., Duan, P., Li, S., Habicht, C.S., Pinkston, S.D., Vinueza, R.N., Kenttämaa, H.I.: Regioselective ion-molecule reactions for the mass spectrometric differentiation of protonated isomeric aromatic diamines. Analyst 132, 452-454 (2008)

19. Duan, P., Gillespir, T.A., Winger, B.E., Kenttämaa, H.I.: Identification of the aromatic tertiary $\mathrm{N}$-Oxide functionality in protonated analytes via ion-molecule reactions in mass spectrometers. J. Org. Chem. 73, 48884894 (2008)

20. Vairamani, M., Mirza, U.A., Srinivas, R.: Unusual positive ion reagents in chemical ionization mass spectrometry. Mass Spectrom. Rev. 9, 235$258(1990)$

21. Munson, B.: Development of chemical ionization mass spectrometry. Int. J. Mass Spectrom. 200, 243-251 (2000)

22. Vairamani, M., Srinivas, R., Mirza, U.A.: 1, 2-Dibromoethane as a positive chemical ionization reagent: Application to geometrical isomers. Org. Mass Spectrom. 23, 620-621 (1988)

23. Vairamani, M., Saraswathi, M., Rao, G.K.V.: Mass-spectral study of substituted methyl $(E)$ - and (Z)-cinnamates under 1,2-dibromoethane chemical ionization. Org. Mass Spectrom. 26, 786-788 (1991)

24. Partanen, T., Vainiotalo, P.: Methyl iodide - an interesting reagent for positive ion chemical ionization. Rapid Commun. Mass Spectrom. 11, 881-888 (1997)

25. Tzing, S.H., Ghule, A., Chang, J.Y., Ling, Y.C.: Selective adduct formation by furan chemical ionization reagent in gas chromatography ion trap mass spectrometry. J. Mass Spectrom. 38, 401-408 (2003)

26. Tzing, S.H., Ghule, A., Liu, J.Y., Ling, Y.C.: On-line derivatization gas chromatography with furan chemical ionization tandem mass spectrometry for screening of amphetamines in urine. J. Chromatogr. A 1137, 76-83 (2006)

27. Tzing, S.H., Ghule, A., Chang, J.Y., et al.: Chemical ionization of substituted naphthalenes using tetrahydrofuran as a reagent in gas chromatography with ion trap mass spectrometry. Rapid Commun. Mass Spectrom. 17, 811-815 (2003)

28. Pointet, K., Milliet, A., RenouGonnord, M.F., FleuratLessard, P., Levart, M.: Mass spectrometric differentiation of isomeric polycyclic aromatic hydrocarbons by chemical ionization with diethyl ether, tetrahydrofuran and dimethyl carbonate. Eur. Mass Spectrom. 3, 281-290 (1997) 
29. Bure, C., Sellier, N., Lesage, D., Fournier, F., Tabet, J.C.: Ion-molecule reactions with dimethyl ether and dimethyl-d6 ether: Differentiation of four isomers contained in patchouli essential oil. Rapid Commun. Mass Spectrom. 14, 872-877 (2000)

30. Gervat, V., Fournier, F., Perlat, M.C., Tabet, J.C.: Ion-molecule reactions in the gas phase. Part xxii. Reactivity of the cis- and transindanediols with dimethyl ether ions. J. Am. Soc. Mass Spectrom. 8, 610-619 (1997)

31. Bose, A.K., Prakash, O., Geng, Y.H., Edasery, J.: Novel use of crown ethers in chemical ionization mass spectrometry. J. Org. Chem. 48, 1780-1782 (1983)

32. McAnoy, A.M., Williams, J., Paine, M.R.L., Rogers, M.L., Blanksby, S.J.: Ion-molecule reactions of O, S-dimethyl Methylphosphonothioate: Evidence for intramolecular sulfur oxidation during VX perhydrolysis. J. Org. Chem. 74, 9319-9327 (2009)

33. Zhang, J.X., Ji, H.W., Sun, S.H., Mao, D.B., Liu, H.W., Guo, Y.L.: Selective determination of pyridine alkaloids in tobacco by PFTBA ions-analyte molecule reaction ionization ion trap mass spectrometry. $J$. Am. Soc. Mass Spectrom. 18, 1774-1782 (2007)

34. Aguera, A., Mezcua, M., Mocholi, F., Vargas-Berenguel, A., FernandezAlba, A.R.: Application of gas chromatography-hybrid chemical ionization mass spectrometry to the analysis of diclofenac in wastewater samples. $J$. Chromatogr. A 1133, 287-292 (2006)

35. Yang, C.H., Khan, N.A., Wu, H.F.: Differentiation and quantification of xylene isomers by combining headspace solid-phase microextractiongas chromatography and self-ion molecule reaction in an ion trap tandem mass spectrometry. J. Sep. Sci. 31, 3050-3057 (2008)

36. Flamini, R., Vedova, A.D., Cancian, D., Panighel, A., Rosso, M.D.: GC/MS-positive ion chemical ionization and MS/MS study of volatile benzene compounds in five different woods used in barrel making. $J$. Mass Spectrom. 42, 641-646 (2007)

37. Lowe, R.H., Barnes, A.J., Lehrmann, E., Freed, W.J., Kleinman, J.E., Hyde, T.M., Herman, M.M., Huestis, M.A.: A validated positive chemical ionization GC/MS method for the identification and quanti- fication of amphetamine, opiates, cocaine, and metabolites in human postmortem brain. J. Mass Spectrom. 41, 175-184 (2006)

38. Murty, M.R.V.S., Prabhakar, S., Lakshmi, V.V.S., Saradhi, U.V.R.V., Reddy, T.J., Vairamani, M.: Mass spectral analysis of chloropicrin under negative ion chemical ionization conditions. Anal. Chem. 77, 3406-3410 (2005)

39. Tagami, T., Kajimura, K., Satsuki, Y., Nakamura, A., Okihashi, M., Takatori, S., Kakimoto, K., Obana, H., Kitagawa, M.: Rapid analysis of 56 pesticide residues in natural medicines by GC/MS with negative chemical ionization. J. Nat. Med. 62, 126-129 (2008)

40. PC Spartan Pro, Version 1,0,7; Wavefunction Inc.: Irvine, CA, June 14, 2001.

41. Stewart, J.J.P., Davis, L.P., Burggraf, L.W.: Semiempirical calculations of molecular trajectories: Method and applications to some simple molecular systems. J. Comput. Chem. 8, 1117-1123 (1987)

42. Stewart, J.J.P.: Optimization of parameters for semiempirical methods. I. Method. J. Comput. Chem. 10, 209-220 (1989)

43. Stewart, J.J.P.: Optimization of parameters for semiempirical methods. II. Applications. J. Comput. Chem. 10, 221-264 (1989)

44. Coolidge, M.B., Marlin, J.E., Stewart, J.J.P.: Calculations of molecular vibrational frequencies using semiempirical methods. J. Comput. Chem. 12, 948-952 (1991)

45. Ramirez-Arizmendi, L.E., Yu, Y.Q., Kenttamaa, H.I.: Reactivity of Cl$\mathrm{P}+-\mathrm{Cl}$ toward cyclic organic ethers. J. Am. Soc. Mass Spectrom. 10, 379-385 (1999)

46. Farmer, J.B., Henderson, I.H.S., Lossing, F.P., Marsden, D.G.H. Ionization energy determination. In: Linstrom, P.J., Mallard, W.G. (eds.) NIST Chemistry Web Book, NIST Standard Reference Database Number 69, National Institute of Standards and Technology: Gaithersburg MD; http://webbook.nist.gov (2003) March.

47. Nauduri, D., Greenberg, A.: Calculated ionization energies for a series of sesquiterpenes: Comparisons with experimental vertical ionization energies and comments on related structure-activity relationships (SARs). Struct. Chem. 20, 417-421 (2009) 